\title{
Exploring the Relationship Between Burnout and Job Satisfaction Among Clinical Nurses
}

\author{
Yu-Hsia Lee, (RN, MSM) \\ Department of Nursing, MacKay Memorial Hospital, Taiwan (R.O.C.) \\ Mei-Hsiang Lin, (RN, EdD) \\ School of Nursing, National Taipei University of Nursing and Health \\ Sciences, Taiwan (R.O.C.)
}

Doi: 10.19044/esj.2019.v15n3p449 URL:http://dx.doi.org/10.19044/esj.2019.v15n3p449

\begin{abstract}
Aim. The purpose of this study was to explore the associations between burnout and job satisfaction among clinical nurses. Methods: A cross-sectional survey of 295 nurses were recruited from a medical center in Taiwan. Surveys were conducted using a demographic questionnaire, a Job Satisfaction Scale, and a Job Burnout Inventory. Results: The results were as follows: (1) both of the "personal burnout" and "external satisfaction" had the highest mean subscale score; (2) there were significant differences in the "work-related burnout" and the "overall burnout" related to those having children among the participating nurses $(\mathrm{t}=2.13,2.10 \mathrm{p}<.05)$; (3) there was a statistically significant relationship between the burnout, and the job satisfaction; (4) "personal burnout", "work-related burnout", and the "overcommitment to work" were related to the "inner satisfaction" and the "external satisfaction" $(p<.05)$. Conclusion: This study's findings may well provide guidance for the decision-making, and evidence for the need to improve job satisfaction in order to reduce burnout that may encourage nursing staff to retain their present jobs and improve the quality of care provided.
\end{abstract}

Keywords: Nurses, burnout, job satisfaction

\section{Introduction}

As the largest health profession, nurses play a vital role in the delivery of quality health-care services and productivity in health-care organizations (Shin \& Lee, 2016). Liu, Pan, Wen, Chen, and Lin (2010) investigated emergency department nurses and discorered that nursing staff suffer from five stressors among nursing staff. These included a massive casualty event, delayed physician support, overloads of routine work, overloads of assignments, and annoying paper work. Consequently, Chou and Hu (2014) 
addressed that nurses have a relatively higher burnout than other professionals working in other fields. Also exhibit a lower job satisfaction, and burnout, which is denoted as a syndrome or a collection of associated signs or conditions (Akman, Ozturk, Bektas, Ayar, \& Armstrong, 2016). Moreover, Adwan (2014), and Liu, Aungsuroch, \& Yunibhand (2016), job satisfaction is defined as the experienced pleasure of accomplishing assigned work, and the positive emotional situation acquired by the employee as a result of evaluating their job. A variety of population-based studies have shown that high burnout may pose safety risks for patients as well as nurses (Alves \& Guirardello, 2016; Dall'Ora, Griffiths, Ball, Simon, \& Aiken, 2015). According to Yeh, Cheng, Chen, \& Chiu (2008), burnout status can be categorized into four types: personal burnout, work-related burnout, client-related burnout, and over-commitment to work. Akman et al., (2016) indicated that dissatisfaction with work can cause poor job performance, lower productivity, staff turnover, and is costly to organizations. Hence, Caricati et al. (2014) postulated that job satisfaction in staff nurses is of the greatest concern to health care organizations, and there is a pressing need to study the factors that can maintain and/or enhance the satisfaction of the health care professionals.

Nurses' job satisfaction is one of the most important factors in determining individuals' intention to stay or leave a health-care organization (Caricati et al., 2014). Hirschfeld (2000) indicated that job satisfaction consists of an extrinsic and intrinsic component. Intrinsic job satisfaction is how people feel about the nature of the job tasks themselves, while extrinsic job satisfaction is how people feel about the aspects of the work situation that are external to the job tasks. Moreover, empirical research has found a relationship between burnout and job satisfaction. According to Akman et al. (2016) and Rosales, Labrague, \& Rosales (2013), burnout and job satisfaction are negatively correlated. Furthermore, Khamisa, Oldenburg, Peltzer and Ilic (2015) investigated work related stress, burnout, job satisfaction and general health in nurses, and found that burnout and job satisfaction have also been found to be associated with each other as well as poor health outcomes. Alharbi, Wilson, Woods and Usher (2016) investigated 150 Saudi national critical care nurses and found that burnout is a predictor of job satisfaction and, indeed, may be reduced as a result of burnout.

De Simone, Planta and Cicotto (2018) also mentioned that patient satisfaction was positively correlated with a nurses' job satisfaction. However, there are no studies assessing the relationship between sets of burnout and job satisfaction rather than between individual variables among the nurses.The canonical correlation analysis is an appropriate technique when there is a need to analyze the relationship between two meaningful sets of variables(Nimon, Henson, \& Gates, 2010). 
Moreover, Kevin and Kenneth (2007), and Vilsaint, Aiyer, Wilson, Shaw, \& Dishion (2013) indicated that canonical correlation is the principal multivariate technique, which is a multivariate statistical technique used for analyzing the relationships between two sets of variables, a predicator set and a criterion set. Therefore, this study has investigated the relationships between the sets of variables rather than between the individual variables.

\section{Study aim}

The purpose of this study was to examine the relationship between two sets of variables among nurses using an advanced multivariate analysis technique. The first set comprised of the participants' burnout including personal burnout, work-related burnout, client-related burnout, and overcommitment to work. The second set of variables was composed of the two job satisfaction scores including inner satisfaction and external satisfaction. The relative contribution of each variable to the extracted canonical functions was measured.

\section{Methods}

\section{Design and subjects}

A cross-sectional design which used a self-administered questionnaire survey was employed. A convenient sampling was utilized to collect the data. A total of 295 participates were recruited.

\section{Instruments}

Demographic variables

The demographic data included age, nursing seniority, level of educational, marital status, and number of children.

\section{Job Satisfaction Scale}

The variable job satisfaction utilized the Job Satisfaction Scale (Yeh, Liu, Ke, Chen, \& Wang, 2004), being an instrument containing 20 items, to measure the frequency dimension of the two aspects of inner satisfaction and external satisfaction. Scoring of the job satisfaction scale used a 5-point Likert scale ranging from 1 point (very dissatisfied) to 5 points (very satisfied). Item responses were summed or averaged to create a total score, the lower the score the lower the level of job satisfaction. Cronbach's $\alpha$ values were 0.92 and 0.80 for the original Job Satisfaction Scale instrument by Yeh et al., (2004). In the present study, Cronbach's alpha for this instrument was .88 and 0.81 , respectively. 


\section{The Job Burnout Inventory}

The variable burnout status was assessed by a Chinese version of the Occupational Burnout Inventory (Yeh et al., 2008), which has 21 items categorized into four subscales: personal burnout (5 items), work-related burnout (5 items), client-related burnout (6 items), and over-commitment to work (5 items). All items used a Likert-type, five-response category scale: from always (score 100) to never (0) or very seriously (100) to very slightly (0). A higher score indicated greater burnout. According to Yeh et al., (2008), the reliability value for the Occupational Burnout Inventory is 0.84 and the range for the subscale is $0.84-0.92$. In the present study, this tool is a reliable measure of burnout among nurses with the Cronbach's alpha values of 0.89 for personal burnout, 0.89 for work-related burnout, 0.92 for client-related burnout, and 0.83 for over-commitment to work.

\section{Ethical considerations}

This study was approved by the research ethics committees of the hospital (approval number: 103-4962B). The objectives of the study and the questionnaire were explained to all the participants and they were assured of the anonymity and confidentiality of their responses. Participation in the study was voluntary. All the participants provided a signed informed consent to participate.

\section{Data Analysis}

The statistics application of SPSS/Windows 20.0 (SPSS, Inc., Chicago, IL) was used for data archiving and statistical analysis. Descriptive statistics of frequency, percentage, mean, and standard deviation were performed. Differences in burnout, job satisfaction, and demographic data were measured using the student's $t$ test. Correlations between burnout and job satisfaction were calculated using Pearson's product-moment correlation. Canonical correlation was used to identify the predictors of job satisfaction, and a $p$ value of less than .05 was considered statistically significant.

\section{Results}

The majority of the participants were unmarried (69.2\%), and 92.5\% had received a college education. The mean age of all was 30.27 years $(\mathrm{SD}=$ 6.55). Among the burnout factors, "Personal burnout" had the highest mean score and "client-related burnout" had the lowest. Among the job satisfaction factors, "external satisfaction" had the highest mean score. The descriptive statistics of the study subjects are as presented in Table 1. 
Table 1. Participants' Demographics $\mathrm{n}=295$

\begin{tabular}{llll}
\hline Variables & $\mathrm{n}$ & $\%$ & $\mathrm{M} \pm \mathrm{SD}$ \\
\hline Age & & $30.27 \pm 6.55$ \\
Nursing seniority & & $8.01 \pm 6.12$ \\
$\begin{array}{l}\text { Educational degree } \\
\quad \text { College }\end{array}$ & 273 & 92.5 & \\
$\quad$ University & 22 & 7.5 & \\
Marital status & & & \\
$\quad$ Unmarried & 204 & 69.2 & \\
$\quad$ Married & 91 & 30.8 & \\
Have children & & & \\
$\quad$ Yes & 80 & 27.1 & \\
$\quad$ no & 215 & 72.9 & \\
Burnout & & & $45.41 \pm 15.54$ \\
$\quad$ personal burnout & & & $51.51 \pm 18.43$ \\
$\quad$ work-related burnout & & & $48.69 \pm 20.09$ \\
$\quad$ client-related burnout & & & $39.70 \pm 20.46$ \\
$\quad$ over-commitment to work & & & $31.75 \pm 19.32$ \\
Job satisfaction & & & $3.76 \pm .39$ \\
$\quad$ inner satisfaction & & & $3.85 \pm .42$ \\
$\quad$ external satisfaction & & & \\
\hline
\end{tabular}


Table 2.Differences among Demographics, Burnout, and Job Satisfaction Variables

\begin{tabular}{|c|c|c|c|c|c|c|c|c|}
\hline \multirow{3}{*}{ Variables } & \multicolumn{5}{|l|}{ burnout } & \multicolumn{3}{|c|}{ job Satisfaction } \\
\hline & $\begin{array}{l}\text { personal } \\
\text { burnout }\end{array}$ & $\begin{array}{l}\text { work-related } \\
\text { burnout }\end{array}$ & $\begin{array}{l}\text { client-related } \\
\text { burnout }\end{array}$ & $\begin{array}{l}\text { over-commitment } \\
\text { to work }\end{array}$ & overall burnout & $\begin{array}{l}\text { ner } \\
\text { satisfaction }\end{array}$ & $\begin{array}{l}\text { external } \\
\text { satisfaction }\end{array}$ & $\begin{array}{l}\text { overall Job } \\
\text { satisfaction }\end{array}$ \\
\hline & $M \pm S D$ & $M \pm S D$ & $M \pm S D$ & $M \pm S D$ & $M \pm S D$ & $M \pm S D$ & $M \pm S D$ & $M \pm S D$ \\
\hline \multicolumn{9}{|c|}{ Educational degree } \\
\hline College & $50.97 \pm 18.20$ & $48.28 \pm 19.87$ & $39.91 \pm 19.99$ & $41.58 \pm 19.10$ & $45.18 \pm 15.23$ & $3.77 \pm .39$ & $3.84 \pm .42$ & $3.80 \pm .38$ \\
\hline University & $58.18 \pm 20.38$ & $53.86 \pm 22.51$ & $37.12 \pm 26.09$ & $43.86 \pm 22.25$ & $48.26 \pm 19.13$ & $3.75 \pm .37$ & $3.90 \pm .40$ & $3.83 \pm .35$ \\
\hline$t$-value & -1.77 & -1.25 & .61 & -.53 & -.89 & .12 & -.61 & -.27 \\
\hline \multicolumn{9}{|l|}{ Marital status } \\
\hline Unmarried & $50.49 \pm 17.81$ & $45.66 \pm 18.90$ & $37.18 \pm 17.68$ & $40.66 \pm 19.20$ & $43.50 \pm 13.99$ & $3.73 \pm .40$ & $3.82 \pm .44$ & $3.77 \pm .39$ \\
\hline Married & $51.96 \pm 18.73$ & $50.05 \pm 20.49$ & $40.83 \pm 21.54$ & $42.23 \pm 19.40$ & $46.27 \pm 16.14$ & $3.78 \pm .38$ & $3.86 \pm .41$ & $3.82 \pm .37$ \\
\hline$t$-value & -.63 & -1.73 & -1.52 & -.64 & -1.41 & -1.14 & -.80 & -1.04 \\
\hline \multicolumn{9}{|l|}{ Have children } \\
\hline Yes & $52.16 \pm 18.23$ & $50.21 \pm 20.20$ & $40.99 \pm 21.22$ & $42.91 \pm 19.26$ & $46.57 \pm 15.68$ & $3.77 \pm .39$ & $3.86 \pm .41$ & $3.82 \pm .37$ \\
\hline No & $49.75 \pm 18.97$ & $44.63 \pm 19.32$ & $36.25 \pm 17.96$ & $38.63 \pm 19.27$ & $42.31 \pm 14.79$ & $3.74 \pm .39$ & $3.81 \pm .45$ & $3.78 \pm .39$ \\
\hline$t$-value & .99 & $2.13^{*}$ & 1.77 & 1.69 & $2.10^{*}$ & .58 & .89 & .80 \\
\hline
\end{tabular}

Each dimension of burnout and job satisfaction were analyzed using the participants' demographics (Table 2). With regard to work-related burnout, the results showed significant differences in those that have children among the participants $(\mathrm{t}=2.13, \mathrm{p}<.05)$. The results for overall burnout showed significant differences in those that have children among the participants $(\mathrm{t}=2.10, \mathrm{p}<.05)$. No significant differences were shown as to educational degree, marital status, burnout, and job satisfaction variables. 
Table 3. Relationship between burnout, and job satisfaction

\begin{tabular}{lrrrrrrrrrrr}
\hline \multicolumn{1}{c}{ Variables } & \multicolumn{1}{c}{1} & 2 & 3 & 4 & 5 & 6 & 7 & 8 & 9 & 10 \\
\hline 1.age & 1 & & & & & & & & & \\
2.Nursing seniority & $.92^{* *}$ & 1 & & & & & & & \\
3.Personal burnout & -.037 & -.06 & 1 & & & & & & & \\
4.Work-related burnout & $-.15^{* *}$ & $-.18^{* *}$ & $.77^{* *}$ & 1 & & & & & & \\
5.Client-related burnout & $-.15^{* *}$ & $-.17^{* *}$ & $.47^{* *}$ & $.60^{* *}$ & 1 & & & & & \\
6.Over-commitment to work & $-.13^{*}$ & -.11 & $.43^{* *}$ & $.49^{* *}$ & $.25^{* *}$ & 1 & & & & \\
7.Overall burnout & $-.15^{* *}$ & $-.16^{* *}$ & $.83^{* *}$ & $.90^{* *}$ & $.74^{* *}$ & $.68^{* *}$ & & & & \\
8.Inner satisfaction & .01 & .03 & .07 & .03 & $-.13^{*}$ & $.22^{* *}$ & .05 & 1 & & \\
9.External satisfaction & .01 & -.01 & $.20^{* *}$ & $.20^{* *}$ & -.09 & $.33^{* *}$ & $.20^{* *}$ & $.73^{* *}$ & 1 & \\
10.Overall satisfaction & .01 & .01 & $.15^{* *}$ & $.13^{*}$ & $-.12^{*}$ & $.30^{* *}$ & $.14^{*}$ & $.92^{* *}$ & $.93^{* *}$ & & 1 \\
${ }^{*} \mathrm{p}<.05 ;{ }^{* *} \mathrm{p}<.01$ & & & & & & & & & &
\end{tabular}

Table 3 shows the bivariate correlation among all of the variable. There was a statistically significant relationship between the inner satisfaction mean scores and the client-related burnout $(\mathrm{r}=-.13, \mathrm{p}<.05)$, and the overcommitment to work $(\mathrm{r}=.22, \mathrm{p}<.01)$ subscale scores. A statistically significant relationship between the external satisfaction mean scores and personal burnout $(\mathrm{r}=.20, \mathrm{p}<.01)$, work-related burnout $(\mathrm{r}=.20, \mathrm{p}<.01)$, over-commitment to work $(\mathrm{r}=.33, \mathrm{p}<.01)$ and overall burnout $(\mathrm{r}=.20, \mathrm{p}<$ .01) subscale scores were noted. Furthermore, there was a statistically significant relationship between the overall satisfaction mean scores and personal burnout $(\mathrm{r}=.15, \mathrm{p}<.01)$, work-related burnout $(\mathrm{r}=.13, \mathrm{p}<.05)$, client-related burnout( $\mathrm{r}=-.12, \mathrm{p}<.05)$, over-commitment to work $(\mathrm{r}=.30, \mathrm{p}$ $<.01)$, and overall burnout $(\mathrm{r}=.14, \mathrm{p}<.05)$ subscale scores.

Table 4. Canonical Relationship between Burnout and Job Satisfaction

\begin{tabular}{|c|c|c|c|c|c|}
\hline \multirow{2}{*}{$\begin{array}{l}\text { X variable } \\
\text { (burnout) }\end{array}$} & \multicolumn{2}{|c|}{ Canonical factor } & \multirow{2}{*}{$\begin{array}{c}\text { Y variable } \\
\text { (job satisfaction) }\end{array}$} & \multicolumn{2}{|c|}{ Canonical factor } \\
\hline & $\chi_{1}$ & $x_{2}$ & & $\eta_{1}$ & $\eta_{2}$ \\
\hline Personal burnout & .42 & -.53 & Inner satisfaction & .67 & .73 \\
\hline Work-related burnout & .43 & -.86 & & & \\
\hline Client-related burnout & -.16 & -.56 & & & \\
\hline $\begin{array}{l}\text { Over-commitment to } \\
\text { work }\end{array}$ & .68 & -.02 & External satisfaction & .99 & .07 \\
\hline $\begin{array}{l}\text { Extracted variance } \\
\text { percentage }\end{array}$ & .33 & .22 & $\begin{array}{l}\text { Extracted variance } \\
\text { percentage }\end{array}$ & .72 & .27 \\
\hline \multirow[t]{3}{*}{ redundancy ( \% ) } & .51 & .10 & redundancy ( \% ) & .17 & .08 \\
\hline & & & $\rho^{2}$ & .23 & .03 \\
\hline & & & Canonical coefficients $(\rho)$ & $.48^{* *}$ & $.17^{*}$ \\
\hline
\end{tabular}




\section{Prediction Relationship between Burnout and Job Satisfaction}

The question investigated as to whether a significant relationship existed between job satisfaction and the presence of Personal burnout, Workrelated burnout, Client-related burnout, and Over-commitment to work. The predictor (burnout) variables are labeled $\mathrm{X}$; and the criterion (job satisfaction) variables as Y. The significant predictors for job satisfaction were personal burnout, work-related burnout, client-related burnout, and over-commitment to work.

Two significant canonical variates were extracted in the canonical correlation procedure (Table 4). The variance of burnout can be explained by the first $\chi 1$ (at $33 \%$ ), and the second $\chi 2$ (at 22\%), whereas job satisfaction can be explained by the first $\eta 1$ (at 72\%), and the second $\eta 2$ (at 27\%). Both canonical correlations were significant with $\rho 1=.48(\mathrm{p}<0.01)$, and $\rho 2=.17$ $(\mathrm{p}<0.05)$. This indicates that job satisfaction could be explained by burnout. The first predicting factor $(\chi 1)$ explained $23 \%(\rho 12=.23)$ of the variance of the first dependent variable $(\eta 1)$. The index of redundancy of burnout $(\chi 1)$ was .51 , indicating that these two canonical factors of dependent variables $\eta 1$ and $\eta 2$ can explain $50 \%$ and $10 \%$ of the variances of burnout, respectively. The $\eta 1$ was more important than $\eta 2$ when trying to explain the variance of burnout. The redundancy indexes of job satisfaction $(\eta 1)(\eta 2)$ were .17 and .08 , respectively, indicating that these canonical factors of independent variables $\chi 1$ and $\chi^{2}$ explain $17 \%$ and $8 \%$ of the variances of job satisfaction, respectively. The first canonical factor was significantly more important than the second in explaining this variance.

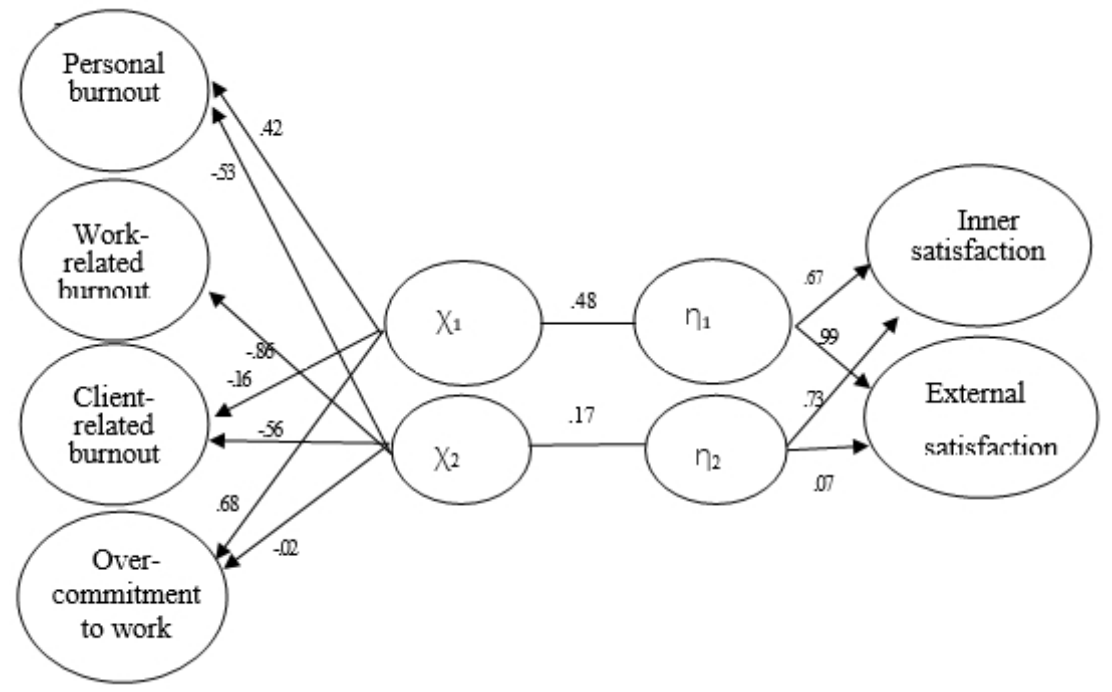

Fig 1. Canonical relationship between burnout and job satisfaction

In the first canonical correlation, "Personal burnout", "Work-related burnout", and "the Over-commitment to work" had a strong relationship with 
the first canonical factor $(\chi 1)$ at levels of $.42, .43$, and .68, respectively; whereas "Inner satisfaction" and "External satisfaction" had a strong relationship with the first canonical factor $(\eta 1)$ of the dependent variables, at a level of .67 and .99. This means that "Inner satisfaction" and "External satisfaction" were closely related with the "Personal burnout", "Work-related burnout", and "the Over-commitment to work". In the second canonical correlation, "Personal burnout", "Work-related burnout", and "Client-related burnout" had a strongly negative relationship with the second canonical factor $(\chi 2)$ at levels of $-.53,-.86$, and -.56, respectively; whereas "Inner satisfaction" had a strong relationship with the second canonical factor $(\eta 2)$ of the dependent variables, at a level of .74. This means that "Inner satisfaction" was closely related with the "Personal burnout", "Work-related burnout", and "Client-related burnout". Additionally, the path diagram representations of the results for first and second canonical variates are as presented in Figure 1.

\section{Discussion}

The purpose of this study was to explore the associations between burnout and job satisfaction among clinical nurses. The mean subscale score of "personal burnout" had the highest mean score. The finding was contradictory to Jacobs, Nwaz, Hood, and Bae (2012), who reported lower scores for personal burnout. The higher average scores obtained in our study were due to the specific medical environment in which this study was undertaken. Chen (2008) pointed out that personal achievement, motivation, work (such as job characteristics, internal rewards and organizational characteristics), also influences job satisfaction. The finding demonstrated that "external satisfaction" had the highest mean subscale score. According to Hirschfeld (2000), extrinsic job satisfaction is how people feel about the aspects of the work situation that are external to the job tasks. A possible explanation for this situation is that job satisfaction concerns satisfaction with pay, supervision, company policy, and the nature of the work (Rothmann, 2010).

The personal burnout, work-related burnout, and the over-commitment to work were related to inner satisfaction and external satisfaction. The finding of the present study was congruent with several previous studies. (Alharbi et al., 2016; Lin, Lin, Cheng, Wu, \& Ou-Yang, 2016). Lin et al., (2016) investigated the relationship between work stress, occupational burnout, and depression in the paediatric intensive care unit's female nurses, and discovered that occupational burnout may exert a partial mediating effect on the relationship between work stress, and depression level. Khamisa et al., (2015) mentioned that burnout and job satisfaction have also been found to be associated with each other as well as poor health outcomes. Akman et al., (2016) investigated the relationship between burnout and job satisfaction of 
pediatric nurses and discovered that scores on the sub-dimensions of job satisfaction (internal, external, and general) satisfaction had crucial effects on emotional exhaustion, depersonalization, and feelings of personal accomplishment.

There was no significant difference between marital status and burnout. The finding of the present study was contradictory with other studies (Akman et al., 2016; Taycan et al., 2006). Additionally, there was no significant difference between having an education degree and burnout. This finding was congruent with a recent study (Akman et al., 2016). The finding of a strong relationship between age, nursing seniority, and burnout was congruent with some studies (Sekol \& Kim, 2014; Taycan, Kutlu, Cimen \& Aydin, 2006). Nevertheless, the finding was contradictory to a study by Akman et al., (2016), which reported no significant difference between years of work and burnout level. A possible explanation for this is that the influence of age on the burnout level might well be related to the advantages of the acquisition of experience and enhanced workplace problem solving. A significant difference was also demonstrated between work-related burnout, overall burnout, and having children. The finding was contradictory to a study by Akman et al., (2016), which reported no significant difference between the number of children and burnout level. This study examines the effect of the two variables of worker and job on job satisfaction, but does not examine the factors of different organizational characteristics. Future studies can include organizational factors in their research.

\section{Conclusion and Recommendation}

The purpose of this study was to examine the relationships between a set of job satisfaction and a set of burnout among nurses using the canonical multivariate analysis. The relative contribution of each variable to the extracted canonical functions was measured. This study's findings may well provide guidance for the decision-making, along with evidence for the need to improve job satisfaction in order to reduce burnout that may encourage the nursing staff to retain their present jobs and improve the quality of care provided.

\section{References:}

1. Adwan, J. Z. (2014) Pediatric nurses' grief experience, burnout and job satisfaction. Journal of Pediatric Nursing, 29 (4), 329-336.

2. Akman, O., Ozturk, C., Bektas, M., Ayar, D., \& Armstrong, M. A. (2016). Job satisfaction and burnout among paediatric nurses. Journal of Nursing Management, 24(7), 923-933. doi: 10.1111/jonm.12399

3. Alharbi, J., Wilson, R., Woods, C., \& Usher, K. (2016). The factors influencing burnout and job satisfaction among critical care nurses: a 
study of Saudi critical care nurses. Journal of Nursing Management, 24(6), 708-717. doi: 10.1111/jonm.1238

4. Alves, D. F. S., \& Guirardello, E. B. (2016). Safety climate, emotional exhaustion and job satisfaction among Brazilian paediatric professional nurses. International Nursing Review, 63, 328-335.

5. Caricati, L., Sala, R., Marletta, G., Pelosi, G., Ampollini, M., Fabbri, A., Ricchi, A., Scardino, M., Artoli, G., \& Mancini, T. (2014). Work climate, work values and professional commitment as predictors of job satisfaction in nurses. Journal of Nursing Management, 22, 984-994.

6. Dall'Ora, C., Griffiths, P., Ball, J., Simon, M., \& Aiken, L. H. (2015). Association of $12 \mathrm{~h}$ shifts and nurses' job satisfaction, burnout and intention to leave: findings from a cross-sectional study of 12 European countries. BMJ Open. 5(9), e008331.

7. De Simone, S., Planta, A., \& Cicotto, G. (2018). The role of job satisfaction, work engagement, self-efficacy and agentic capacities on nurses' turnover intention and patient satisfaction. Applied Nursing Research, 39(2018), 130-140.

8. Hirschfeld, R. R. (2000). Validity studies. Does revising the intrinsic and extrinsic subscales of the Minnesota Satisfaction Questionnaire Short Form make a difference? Educational Psychological Measurement, 60(2), 255-270.

9. Chen, L. H. (2008). Job satisfaction among information system (IS) personnel. Computers in Human Behavior, 24 (2008), 105-118.

10. Chou, L.P., Li, C.Y., \& Hu, S. C. (2014). Job stress and burnout in hospital employees: comparisons of different medical professions in a regional hospital in Taiwan. BMJ Open, 4:e004185 doi: 10. 1136/ bmjopen- 2013- 004185

11. Jacobs, L. M., Nwaz, M. k., Hood, J. L. \& Bae, S. (2012) Burnout among workers in a pediatric health care system. Workplace Health \& Safety 60(8), 335-344.

12. Kevin, S. M., \& Kenneth, A. W. (2007). Canonical correlation reveals important relations between health locus of control, coping, affect and values. Journal of Health Psychology, l0(5), 719- 731.

13. Khamisa, N, Oldenburg, B., Peltzer, K., \& Ilic, D. (2015). Work related stress, burnout, job satisfaction and general health of nurses. International Journal of Environmental Research and Public Health, 12, 652-666. doi: 10. 3390/ ijerph 120100652

14. Lin, T. C., Lin, H. S., Cheng, S. F. Wu, L. M., \& Ou-Yang, M. C. (2016). Work stress, occupational burnout and depression levels: a clinical study of paediatric intensive care unit nurses in Taiwan. Journal of Clinical Nursing, 25, 1120-1130. 
15. Liu, W. W., Pan, F. C., Wen, P. C., Chen, S. J., \& Lin, S. H. (2010). Job stressors and coping mechanisms among emergency department nurses in the Armed Force Hospitals of Taiwan. International Journal of Social, Behavioral, Educational, Economic, Business and Industrial Engineering, 4(7), 1659- 1666.

16. Liu, Y., Aungsuroch, Y., \& Yunibhand, J. (2016). Job satisfaction in nursing: a concept analysis study. International Nursing Review, 63(1), 84-91. doi: 10.1111/ inr. 12215

17. Nimon, K., Henson, R. K., \& Gates, M. S. (2010). Revisiting interpretation of canonical correlation analysis: A tutorial and demonstration of canonical commonality analysis. Multivariate Behavioral Research, 45(4), 702-724.

18. Rosales, R., Labrague, L. J., \& Rosales, G. L. (2013). Nurses' job satisfaction and burnout: Is there a connection? International Journal of Nursing Studies, 2(1), 1-10.

19. Rothmann, S. (2010). Job satisfaction, occupational stress, burnout and work engagement as components of work- related well-being. $S A$ Journal of Industrial Psychology, 34(3), 11-16.

20. Sekol, M. A., \& Kim, S. C. (2014). Job satisfaction, burnout, and stress among pediatric nurses in various specialty units at an acute care hospital. Journal of Nursing Education and Practice, 4(12), 115-124.

21. Shin J. \& Lee E. (2016). The effect of social capital on job satisfaction and quality of care among hospital nurses in South Korea. Journal of Nursing Management, 24(7), 934-942. doi: 10.1111/jonm.12401

22. Taycan, O., Kutlu, L., Cimen, S., \& Aydin, N. (2006). Bir universite hastanesinde calısan hemsirelerde depresyon ve tukenmislik düzeyinin sosyodemografik ozelliklerle iliskisi. Anatolian Journal of Psychiatry, 7, $100-108$.

23. Vilsaint, C. L., Aiyer, S. M., Wilson, M. N., Shaw, D. S., \& Dishion, T. J. (2013). The ecology of early childhood risk: A canonical correlation analysis of children's adjustment, family, and community context in a high-risk sample. The Journal of Primary Prevention, 34(4), 261-277. doi:10.1007/s10935-013-0305-4

24. Yeh, T. F., Liu, T. C., Ke, J. F., Chen, J. T. \& Wang J.W. (2004). The study on motivation attitude, job satisfaction and turnover intention for non-physician formal and temporary employees in a public hospital. The Journal of Health Sciences, 6, 243-259.

25. Yeh, W. Y., Cheng, Y. W., Chen, M. J., \& Chiu, W. H. (2008). Development and validation of an occupational burnout inventory. Taiwan Journal of Public Health, 27, 349-364. 